\title{
Catastrophic complication of an electromagnetic placed postpyloric feeding tube
}

\section{Marloes Veltcamp Helbach, Claudia Savelkoul, Barbara Festen-Spanjer, David H Tjan}

Department of Intensive care, Gelderse Vallei Hospital, Ede, The Netherlands

\section{Correspondence to} Dr David H Tjan, tjand@zgv.nl

Accepted 19 August 2016

CrossMark

\section{To cite: Veltcamp} Helbach M, Savelkoul C

Festen-Spanjer B, et al. BMJ Case Rep Published online: [please include Day Month Year] doi:10.1136/bcr-2016216738

\section{DESCRIPTION}

An 83-year-old woman with Crohn's disease presented at the emergency department with severe abdominal pain. Diagnostic colonoscopy confirmed sigmoid stenosis and pneumodilatation was performed. Post procedure the patient developed tachypnoea, tachycardia, fever and signs of an acute abdomen. Biochemistry showed hyperlactatemia as a sign of bowel hypoperfusion. The patient underwent a subtotal colectomy after a CT scan had revealed cecal rupture. She was admitted to the intensive care unit postoperatively. After extubation, a postpyloric feeding tube was inserted by electromagnetic sensorguided enteral access system (EMS-EAS, Cortrak) in

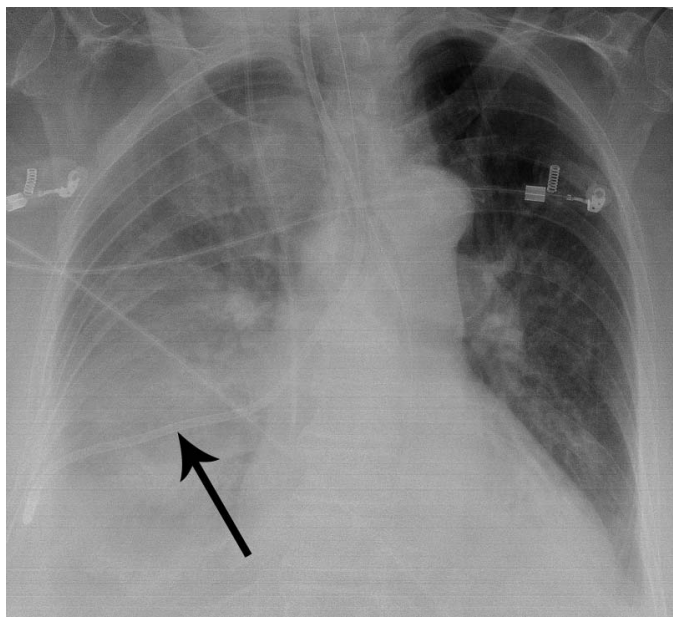

Figure 1 Right-sided endobronchial placement of the feeding tube. three attempts for persistent gastric retention. Within a few hours however, she developed progressive respiratory failure. A chest X-ray (figure 1) showed right-sided endobronchial placement of the feeding tube, which was removed during intubation. Retrospectively, Cortrak tracing showed right-sided endobronchial positioning of the feeding tube as well (figure 2). The patient developed severe aspiration-induced lung injury with hypoxemic failure

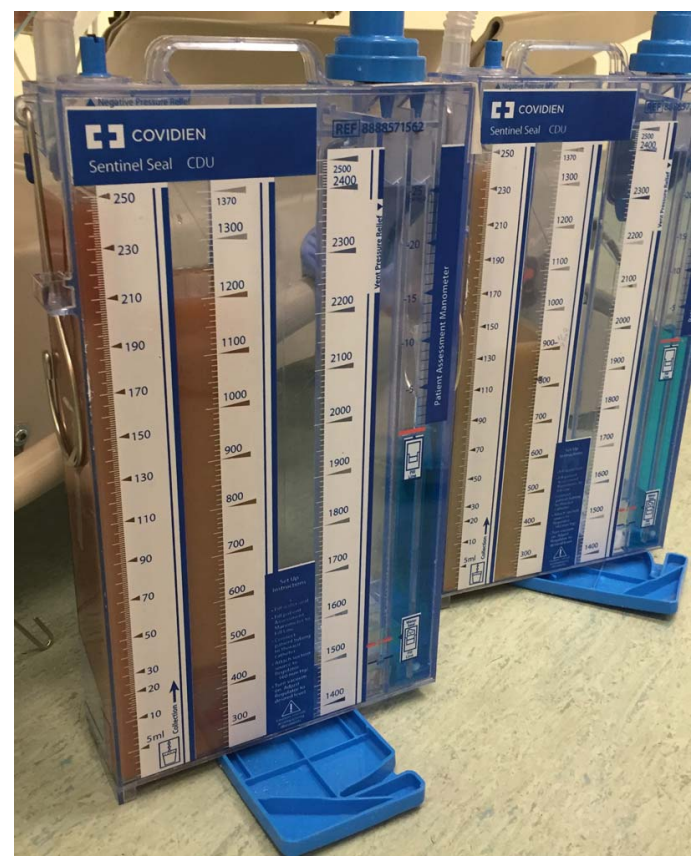

Figure 3 Nutrition-based empyema.

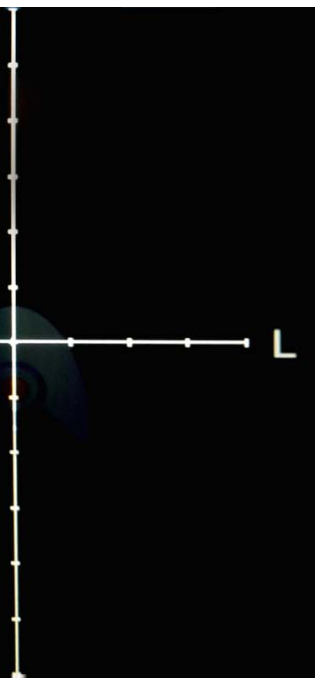

Figure 2 Left: Cortrak tracing of a duodenal placed tube; right: Cortrak tracing in our patient. 


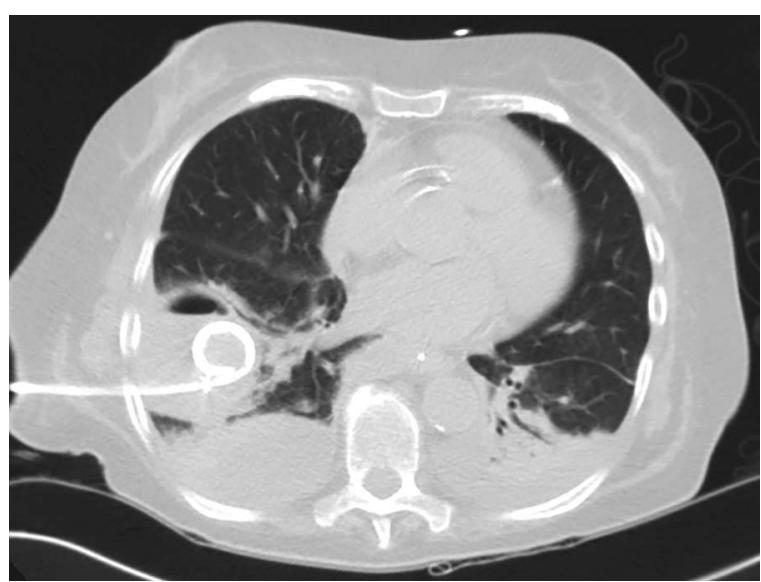

Figure 4 Pigtail catheter drainage of the intrapulmonary abscess.

and prone positioning was required. The pneumonia was complicated by necrosis of the right lower lobe and empyema. Right-sided thoracic drainage produced nutrition-based empyema (figure 3) contaminated with Candida albicans and Pseudomonas aeruginosa in the sputum culture wherefore she was treated with micafungin and ceftazidim with inadequate response. Development of a lung abscess required a lobectomy after intrapulmonary drainage with pigtail catheter (figure 4) was not successful. After 4 months of intensive care treatment, the patient is still in recovery.

Published literature has shown that EMS-EAS reduces the risk of bronchial misplacement of feeding tubes, pneumothorax, and reduces time to start feeding and the need for standard chest X-ray. ${ }^{1-3}$ However, this case illustrates the need for accurate interpretation of EMS-EAS tracing and requires adequate training and experience.

\section{Learning points}

- Sufficient experience of placement by EMS-EAS of postpyloric feeding tubes and accurate interpretation of the tracing are required to guarantee correct positioning.

- Chest X-ray confirmation of correct positioning of the feeding tube by EMS-EAS should be carefully considered in patients with suspected misplacement.

- Misplaced intrapulmonary feeding tubes may cause catastrophic complications.

Contributors MVH is responsible for admitting the patient to the ICU, participated in writing the article (and revision) and received informed consent from the patient. CS is responsible for intubation of the patient and participated in writing the article (and revision). BFS is responsible for intubation of the patient and critically revised the article. DHT closely involved in patient's stay at ICU and critically revised the article. MVH and CS are guarantors.

Competing interests None declared.

Patient consent Obtained.

Provenance and peer review Not commissioned; externally peer reviewed.

\section{REFERENCES}

1 Holzinger U, Brunner R, Miehsler W, et al. Jejunal tube placement in critically ill patients: a prospective, randomized trial comparing the endoscopic technique with the electromagnetically visualized method. Crit Care Med 2011;39:73-7.

2 Powers J, Luebbehusen M, Spitzer T, et al. Verification of an electromagnetic placement device compared with abdominal radiograph to predict accuracy of feeding tube placement. J Parenter Enter Nutr 2011;35:535-9.

3 Smithard D, Barrett NA, Hargroves D, et al. Electromagnetic sensor-guided enteral access systems: a literature review. Dysphagia 2015;30:275-85.

Copyright 2016 BMJ Publishing Group. All rights reserved. For permission to reuse any of this content visit

http://group.bmj.com/group/rights-licensing/permissions.

BMJ Case Report Fellows may re-use this article for personal use and teaching without any further permission.

Become a Fellow of BMJ Case Reports today and you can:

- Submit as many cases as you like

- Enjoy fast sympathetic peer review and rapid publication of accepted articles

- Access all the published articles

- Re-use any of the published material for personal use and teaching without further permission

For information on Institutional Fellowships contact consortiasales@bmjgroup.com

Visit casereports.bmj.com for more articles like this and to become a Fellow 